\title{
50 years of organised healing in the UK: should we celebrate?
}

Spiritual healers believe they can channel healing energy into patients' bodies to bring about an improvement or cure of an illness. Many variations of the theme exist and terminology is confusing: distant healing, faith healing, intercessory prayer, Johrei, Reiki, and therapeutic touch. About 1400 healers are registered in the UK. According to the Department of Health-sponsored patient guide, 'research has shown some benefit in many areas including: healing of wounds, chronic conditions such as migraine or irritable bowel syndrome, reducing side-effects of chemotherapy and radiotherapy for people with cancer, contributing to pain relief, helping relaxation, improving sleep patterns, reducing tension, stress and anxiety, providing emotional and spiritual support, contributing to a sense of wellbeing."1

Currently, the National Federation of Spiritual Healers, (NFSH), the largest professional organisation of healers in the UK (>5000 members), is marking its golden jubilee. Looking at their website (http://www.nfsh.org.uk), one might feel like celebrating the occasion. It states that 'the $\mathrm{NFSH}$ has been working to raise standards in the healing field'. Bravo! Even the thorny issue of evidence is not dodged: 'need to see the scientific evidence ... At present most of the evidence for healing is anecdotal or observational. We'd like to see more studies take place to help prove the remarkable effects of this natural therapy.' Such self-critical appraisal seems laudable, unless, of course, one happens to know the facts.

A systematic review of healing studies included 23 placebo-controlled randomised controlled trials with almost 3000 patients. $^{2}$ Even though half of these investigations generated positive results, no firm conclusions could be drawn due to numerous methodological limitations of the primary data. An update of this review included 17 further clinical trials. ${ }^{3}$ Collectively these data shifted the evidence against the notion that healing might be more than a placebo. Cochrane reviews failed to show that therapeutic touch promotes wound healing, ${ }^{4}$ or that intercessory prayer alleviates ill health. ${ }^{5}$ The two largest healing trials $(n=1493$ and 748) were published recently. Both failed to show that intercessory prayer had any positive effect on outcomes after heart surgery. ${ }^{6,7}$

If the misleading information on the NFSH website and the UK 'official' patient guide ${ }^{1}$ were an exception, none of this would matter much. But woefully inadequate or blatantly wrong guidance on alternative medicine seems to be the rule rather than the exception. If we want to change this precarious situation, it is important to demonstrate how the public is systematically being deluded. The deceptions are relatively obvious when they relate to the plethora of alternative treatments claiming to cure cancer. Recent in-depth analyses, however, show that they can be much more insidious. ${ }^{8-11}$ The NFSH website states that there is a lack of sound evidence 'to prove the remarkable effects' of healing. This is lying by omission because it fails to mention that around 50 controlled clinical trials and several systematic reviews are now available and that, collectively, these data fail to demonstrate effectiveness.

Once we have identified this continuous and dangerous deception of the public, we should take action. Unfortunately, UK officials seem to be on the side of the deceptors $^{1}$ - unlike in Canada where the Competition Bureau recently launched a project of education and enforcement against this type of health fraud. Its deputy commissioner was quoted as stating 'Consumers should be sceptical of healthrelated products or services that look too good to be true, and should always speak to a health care professional before trying any new treatment'. ${ }^{12}$ The NFSH might 'like to see more studies' but the public deserves more honesty.

\section{Edzard Ernst}

\section{REFERENCES}

1. The Prince's Foundation for Integrated Health. Complementary Healthcare: a guide. London: The Prince's Foundation for Integrated Health, 2005. http://www.fih.org.uk/information_library/complem entary_healthcare_a_guide/index.html (accessed 8 May 2008).

2. Astin JA, Harkness EF, Ernst E. The efficacy of 'distant healing': a systematic review of randomized trials. Ann Intern Med 2000; 132: 903-910.

3. Ernst E. Distant healing — an 'update' of a systematic review. Wien Klin Wochenschr 2003; 115: 241-245.

4. O'Mathuna DP, Ashford RL. Therapeutic touch for healing acute wounds. Cochrane Database Syst Rev 2003; 4: CD002766.

5. Roberts L, Ahmed I, Hall S. Intercessory prayer for the alleviation of ill health. Cochrane Database Syst Rev 2000; 2: CD000368.

6. Benson H, Dusek JA, Sherwood JB, et al. Study of the Therapeutic Effects of Intercessory Prayer (STEP) in cardiac bypass patients: a multicenter randomized trial of uncertainty and certainty of receiving intercessory prayer. Am Heart J 2006; 151: 934-942.

7. Krucoff MW, Crater SW, Gallup D, et al. Music, imagery, touch, and prayer as adjuncts to interventional cardiac care: the Monitoring and Actualisation of Noetic Trainings (MANTRA) II randomised study. Lancet 2005; 366: 211-217.

8. Hurley D. Natural causes: death, lies, and politics in America's vitamin and herbal supplement industry. New York: Broadway Books, 2006.

9. Bausell RB. Snake oil science: the truth about complementary and alternative medicine. New York: Oxford University Press, 2007.

10. Singh S, Ernst E. Trick or treatment? Alternative medicine on trial. London: Bantam Press, 2008.

11. Shapiro R. Suckers: how alternative medicine makes fools of us all. London: Harvill Secker, 2008.

12. Anonymous. Project false hope unveiled - competition bureau combats cancer fraud through education and enforcement. Ottawa: Industry Canada, 2008. http://www.ic.gc.ca/cmb/welcomeic.nsf/261ce500dfcd $7259852564820068 \mathrm{dc} 6 \mathrm{~d} / 85256 \mathrm{a} 5 \mathrm{~d} 006 \mathrm{~b} 97208525740$ a 004d408c!OpenDocument (accessed 8 May 2008).

DOI: 10.3399/bjgp08X302835 